\title{
Vocal fatigue in voice professionals: collecting data and acoustic analysis
}

Karina Evgrafova, Vera Evdokimova, Pavel Skrelin, Tatiana Chukaeva

Department of Phonetics, Saint Petersburg State University, Russia

https://doi.org/10.36505/ExLing-2016/07/0011/000270

\begin{abstract}
The present study examines acoustic manifestations of the vocal fatigue in three groups of voice professionals (pronunciation teachers, professional speakers and tourist guides) who seem to be particularly susceptible to vocal loading. In the paper data collecting and the non-fatigue/fatigue speech corpus are described. The detailed acoustic analysis of the data obtained is presented. The results of the acoustic analysis showed a consistent dependency between acoustic parameters and vocal fatigue in terms of F0, jitter and shimmer values. The results can contribute to objective voice examinations and automatic voice pathology detection.
\end{abstract}

Key words: vocal fatigue, acoustic analysis, voice professionals, speech corpora

\section{Introduction}

Vocal fatigue is a voice disorder which particularly concerns professional voice users and can lead to serious pathological conditions Teachers, singers, actors, guides and all types of professional speakers that require prolonged voice use are identified as an at-risk group for developing vocal disorders. The symptoms of vocal fatigue are various and explained by the physiologic mechanisms of vocal production. There exist many studies on vocal fatigue providing various concepts of the phenomenon. However, there is no universally accepted definition. It can be viewed either as a voice disorder caused by other pathological voice conditions or as a separate voice problem resulting from prolonged and excessive voice use [10]. In this study the vocal fatigue is understood as a separate phenomenon caused by excessive professional voice load which results in auditory perceptual and acoustic changes in the voice signal and can lead to serious pathological conditions. The present study paper is aimed to describe the data collecting for the non-fatigue/fatigue speech corpus and to present the results of acoustic analysis.

\section{Methods}

The methodologies that attempt to induce vocal fatigue in experiment participants vary across numerous works on the vocal fatigue [1-9]. In most studies the vocal fatigue is induced artificially as a result of reading

ExLing 2016: Proceedings of $7^{\text {th }}$ Tutorial and Research Workshop on Experimental Linguistics, 27 June - 2 July 2016, Saint Petersburg, Russia 
or speaking tasks of various types. The results described are inconsistent and often conflicting. The conditions of our experiment seem to be more realistically challenging. 20 male and female subjects were recorded. They involved pronunciation teachers with average work experience of 7 years, professional speakers (broadcasters) and tour guides with the work experience not less than 5 years. No one had pathological voice problems. The participants were asked to read at habitual loudness a four minute phonetically representative text.

The teachers were recorded before and after a 7 hour teaching day. The tour guides were recorded before and after 3 hour non-stop excursion and professional speakers - before and after 3 hour non-stop interview/3 hour non-stop recording of a book. All the subjects were asked to fill in a special questionnaire before each type of the recordings. In the questionnaire they evaluated their physical state, mood and a level of activity. The recordings were made in the recording studio at the Department of Phonetics, Saint Petersburg State University.

\section{Results}

We calculated (in Praat) a number of acoustic parameters based on formant values, jittter, shimmer, pitch and loudness which can help detecting the absence/presence of voice fatigue in a given speech sample. The parameters which seem to be most important for automatic detection are the mean value of $\mathrm{F} 0$, jitter and shimmer values.

The calculations showed that the main tendency for both male and female speakers was the increase in the mean value of $\mathrm{F} 0$ in the fatigued speech across all the speaker groups. However, the jitter values become lower. As to the shimmer value, there can be seen the decrease in fatigued female voices and the increase in fatigued male voices. The tables 1-3 below show the results.

Table 1. F0 and duration mean values. Non-fatigue vs. fatigue speech.

\begin{tabular}{|c|c|c|c|c|}
\hline & & Duration (sec) & Unvoiced parts (\%) & Mean F0 \\
\hline \multirow[t]{2}{*}{ Female } & non-fatigue & 214 & 45,7 & 209 \\
\hline & fatigue & 220 & 47,0 & 212 \\
\hline \multirow[t]{2}{*}{ Male } & non-fatigue & 217 & 48,1 & 124 \\
\hline & fatigue & 213 & 46,1 & 130 \\
\hline \multirow[t]{2}{*}{ All } & non-fatigue & 215 & 46,4 & 185 \\
\hline & fatigue & 218 & 46,7 & 188 \\
\hline
\end{tabular}


Vocal fatigue in voice professionals: collecting data and acoustic analysis 61

Table 2. Jitter mean values. Non-fatigue vs. fatigue speech.

\begin{tabular}{|c|c|c|c|c|c|c|}
\hline & \multicolumn{5}{|l|}{ Jitter } \\
\hline & & & $\begin{array}{l}\text { local, } \\
\text { absolute (seconds) }\end{array}$ & rap $\%$ & ppq5 \% & $\operatorname{ddp} \%$ \\
\hline \multirow[t]{2}{*}{ Female } & \begin{tabular}{|l|} 
non- \\
fatigue
\end{tabular} & 2,283 & 0,00011 & 1,002 & 1,051 & 3,008 \\
\hline & fatigue & 2,208 & 0,008578921 & 0,97 & 1,036 & 2,91 \\
\hline \multirow[t]{2}{*}{ Male } & $\begin{array}{l}\text { non- } \\
\text { fatigue }\end{array}$ & 3,239 & 0,000272208 & 1,273 & 1,421 & 3,82 \\
\hline & fatigue & 2,888 & 0,000228958 & 1,085 & 1,229 & 3,254 \\
\hline \multirow[t]{2}{*}{ All } & $\begin{array}{l}\text { non- } \\
\text { fatigue }\end{array}$ & 2,556 & 0,000156442 & 1,08 & 1,157 & 3,24 \\
\hline & fatigue & 2,403 & 0,006036776 & 1,003 & 1,091 & 3,008 \\
\hline
\end{tabular}

Table 3. Shimmer mean values. Non-fatigue vs. fatigue speech.

\begin{tabular}{|c|c|c|c|c|c|c|c|}
\hline & \multicolumn{6}{|c|}{ Shimmer } \\
\hline & & local \% & $\begin{array}{l}\text { local, } \\
(\mathrm{dB})\end{array}$ & $\mathrm{db} \mid \begin{array}{l}\mathrm{apq} 3 \\
\%\end{array}$ & \begin{tabular}{|l|} 
apq5 \\
$\%$
\end{tabular} & $\begin{array}{l}\text { apq11 } \\
\% \\
\%\end{array}$ & \begin{tabular}{|l|}
$d d a$ \\
$\%$
\end{tabular} \\
\hline \multirow[t]{2}{*}{ Female } & $\begin{array}{l}\text { non- } \\
\text { fatigue }\end{array}$ & 8,022 & 0,833 & 2,653 & 4,068 & 7,871 & 7,96 \\
\hline & fatigue & 8,108 & 0,837 & 2,666 & 4,168 & 8,008 & 7,998 \\
\hline \multirow[t]{2}{*}{ Male } & $\begin{array}{l}\text { non- } \\
\text { fatigue }\end{array}$ & 11,003 & 1,063 & 3,777 & 5,775 & 12,18 & 11,33 \\
\hline & fatigue & 10,377 & 1,015 & 3,521 & 5,387 & 11,28 & 10,56 \\
\hline \multirow[t]{2}{*}{ All } & $\begin{array}{l}\text { non- } \\
\text { fatigue }\end{array}$ & 8,874 & 0,898 & 2,974 & 4,556 & 9,103 & 8,923 \\
\hline & fatigue & 8,756 & 0,887 & 2,91 & 4,516 & 8,943 & 8,731 \\
\hline
\end{tabular}

There is also difference in the amount of pauses and their duration between the female and male fatigued recordings. The whole number of pauses tends to increase in the female fatigued speech while the number of pauses in the male fatigued speech decreases. The duration of pauses in the fatigued speech increases both in the male and female recordings. 


\section{Conclusions}

The results of the voice acoustic analysis of the fatigued speech in comparison with the non-fatigued speech showed a consistent dependency between acoustic parameters and vocal fatigue. The parameters which are affected by the vocal fatigue are the F0, jitter and shimmer values, the duration and number of pauses. The differences in the acoustic parameters before and after vocal loading mainly seem to reflect increased muscle activity as a consequence of excessive vocal loading.

The results can contribute to objective voice examinations and automatic voice pathology detection.

\section{References}

Boucher, V.J. 2008. Acoustic Correlates of Fatigue in Laryngeal Muscles: Findings for a Criterion-Based Prevention of Acquired Voice Pathologies. Journal of Speech, Language, and Hearing Research, vol. 51, 1161-1170.

Caraty, M.J., Montacié, C. 2010. Multivariate Analysis of Vocal Fatigue in Continuous Reading, Proceedings of Interspeech 2010, 470-473.

Kostyk, B.E., Rochet, A.P. 1998. Laryngeal airway resistance in teachers with vocal fatigue: a preliminary study. Journal of Voice, vol. 12, 287-299.

Sala, E., Airo, E., Olkinuora, P. et al, 2002. Vocal Loading among Day Care Center Teachers". Logoped Phoniatr Vocol,vol. 27, 21-28.

Schneider, B. 2006. Effects of Vocal Constitution and Autonomic Stress-Related Reactivity on Vocal Endurance in Female Student Teachers. Journal of Voice, vol. 20, No. 2, 242-250.

Scherer, R.C., Titze, I.R. et al. 1986. Vocal fatigue in a professional voice user. In Transcripts of the Fourteenth Symposium: Care of the Professional Voice, New York: The Voice Foundation, pp.124-130.

Scherer, R.C., Titze, I.R. et al. 1991. Vocal fatigue in a trained and an untrained voice user. Laryngeal Function in Phonation and Respiration, San Diego, Singular Publishing Group, pp. 533-555.

Titze, I. , Lemke, J., Montequin, D. 1997. Populations in the U.S. workforce who rely on voice as a primary tool of trade: a preliminary report. Journal of Voice, vol. 11, 254-259.

Laukkanen, A.M. 1995. On speaking voice exercises. $\mathrm{PhD}$ dissertation, Acta Universitatis Tamperensis, ser A, vol. 445, Tampere: University of Tampere. 